\title{
D1 versus Modified D2 Gastrectomy for Ca Stomach-A Prospective and Comparative Study
}

\author{
Alfar Nafae*, Raiees Ahmad, Amber Aliya, Yawar Nisar, Pervaze Salam, \\ Imtiyaz Ahmad \\ Department of General Surgery SMHS Hospital, Government Medical College, Srinagar, India \\ Email: "dralfarnafae@yahoo.com, mallahraiees@gmail.com
}

Received 9 November 2015; accepted 10 January 2016; published 13 January 2016

Copyright (C) 2016 by authors and Scientific Research Publishing Inc.

This work is licensed under the Creative Commons Attribution International License (CC BY).

http://creativecommons.org/licenses/by/4.0/

(c) (7) Open Access

\section{Abstract}

Background: Carcinoma stomach remains a major malignancy and accounts for $10.4 \%$ of cancer related deaths globally. Despite improvement in chemo-radiotherapy, surgery remains the primary curative modality with special emphasis on lymphadenectomy. However the extent of lymphadenectomy performed by surgeons all over the world differs. Generally speaking, in Japan and Korea, the standard curative protocol would entail a "D2" lymphadenectomy whereas in the western world it would be considered unnecessary and the standard protocol would entail a standard "D1" lymphadenectomy. Thus prompting a newer surgical therapy of modified D2 in dissection in which pancreas and spleen are preserved. Lymph nodes surrounding stomach are divided into 20 stations and these are classified into three groups depending upon the location of the primary tumour. Aims \& Objectives: The aims and objectives are to compare: 1) operative time of modified D2 gastrectomy with that of D1 gastrectomy; 2) operative morbidity and mortality of modified D2 gastrectomy with that of D1 gastrectomy; 3) the disease recurrence between modified D2 \& D1 gastrectomy. Materials \& Method: The study entitled D1 versus modified D2 gastrectomy for Ca stomach-a prospective, comparative study was conducted in the Postgraduate Department of General Surgery, Government Medical College, Srinagar as a prospective, comparative study over a period of three years 2012-2014. Patients with resectable gastric cancer were taken as subjects for the study and were divided in $\mathbf{2}$ groups that were closely matched to avoid any bias. Assessment of both the groups was done in identical fashion as per standard protocol. One group underwent gastrectomy with D1 lymph node dissection whereas the other group underwent gastrectomy with a modified D2 lymph node dissection (spleen and pancreas preservation). The type of lymphadenectomy was decided on randomization (simple random sampling). Results: After comparing the two procedures, it was noted that: 1) modified D2 lymphadenectomy took on an

${ }^{*}$ Corresponding author.

How to cite this paper: Nafae, A., Ahmad, R., Aliya, A., Nisar, Y., Salam, P. and Ahmad, I. (2016) D1 versus Modified D2 Gastrectomy for Ca Stomach-A Prospective and Comparative Study. Surgical Science, 7, 13-26.

http://dx.doi.org/10.4236/ss.2016.71002 
average 2 hours more than D1 gastrectomy; 2) operative mortality was same in both the procedures. Operative morbidity was seen more in modified D2 group than D1 group however this difference was statistically insignificant; 3) number of recurrence was quite significant in D1 group but no recurrence was seen in modified D2 group. Conclusion: On the basis of the study, we recommend that modified D2 gastrectomy is a better procedure than D1 gastrectomy for patients of carcinoma stomach undergoing curative resection.

\section{Keywords}

\section{Carcinoma Stomach, Gastrectomy Curative Resection, Lymphnode Dissection}

\section{Background}

Although the incidence of gastric cancer has declined over the past 30 years worldwide, especially in Western countries, it remains the second leading cause of cancer-related death and accounts for $10.4 \%$ of cancer deaths globally [1] and surgical resection remains the primary therapeutic modality for curable advanced cancer. With regard to surgical procedure, dissection of regional LN is regarded an important part of en bloc resection for gastric cancer. However, there are significant differences in the extent of lymphadenectomy performed by surgeons in different countries. In Japan, D2 dissection has been recommended as standard practice since the 1960s [2]. However, most Western surgeons perform gastrectomy with only D1 dissection, because D1 was associated with less mortality and morbidity [3] [4]. Thus prompting a newer surgical therapy of modified D2 in dissection in which pancreas and spleen are preserved. Lymph nodes surrounding stomach are divided into 20 stations and these are classified into three groups depending upon the location of the primary tumour (Group 1: 1 - 6, Group 2: 7 - 12). D1 gastrectomy is defined as dissection of all the Group 1 nodes (Station 1 - 6), and modified D2 is defined as dissection of all the Group 1 and Group 2 nodes, (Stations 7 - 12), however preserving the spleen and pancreas unless directly involved by tumor extension.

Carcinoma stomach is the second most common malignancy after carcinoma oesophagus in our valley, and almost all patients present to our hospital, the aim of present study is to analyse and compare the benefits of modified D2 lymph node dissection over D1 lymph node dissection for cancer stomach.

\section{Materials and Methods}

The study entitled D1 versus modified D2 gastrectomy for Ca stomach-a prospective, comparative study was conducted in the Postgraduate Department of General Surgery, Government Medical College, Srinagar as a prospective, comparative study over a period of three years 2012-2014. Patients with resectable carcinoma stomach considered for gastrectomy (total or subtotal) were taken as subjects for the study. The study was conducted in the Postgraduate Department of General Surgery, Government Medical College, Srinagar as a prospective, comparative study over a period of three years 2012-2014. Patients with resectable carcinoma stomach considered for gastrectomy (total or subtotal) were taken as subjects for the study. The parameters analysed during the study were: 1) operative time of modified D2 gastrectomy with that of D1 gastrectomy; 2) the operative morbidity and mortality of modified D2 gastrectomy with that of D1 gastrectomy; 3) the disease recurrence between modified D2 gastrectomy and D1 gastrectomy. The patients were aged less than 80 years and in adequate physical condition with no serious comorbid cardio respiratory diseases that would preclude a safe modified D2/D1 lymphadenectomies. Patients were eligible for study if they had not undergone previous gastric surgery and had no coexisting cancer. All the patients were evaluated and assessed according to the proforma including an elaborate history, a detailed clinical examination, routine investigations and specific investigations. Diagnosis of all the patients was confirmed by endoscopic examination and histo-pathological examination of biopsy specimen taken. Preopoerative staging was done by CECT abdomen. After preoperative workup, patients underwent a staging laparotomy in order to exclude potentially non-curative cancer. Patients with stage IV disease were excluded from the study. Patients were randomized to undergo either D1 or modified D2 gastrectomy. In D1 resection, gastrectomy was done with removal of N1 group of lymphnodes and greater omentum; modified D2 resection 
included additional removal of N2 group of lymph nodes and omental bursa. D1 and modified D2 dissection were defined according to the guidelines of the Japanese Research Society for the study of gastric cancer. In these guidelines, 16 different lymph node compartments (stations) are identified surrounding the stomach. In general, the perigastric lymph node stations along the lesser (station 1, 3 and 5) and greater (station 2, 4 and 6) curvature are grouped N1, whereas the nodes along the left gastric (station 7), common hepatic (station 8), celiac (station 9) and splenic (station 10 and 11) arteries are grouped N2.

Splenopancreatectomy was not considered as a routine part of modified D2 gastrectomy; the spleen and pancreas were resected only when involved with tumour. The type of gastrectomy performed (distal/total) was not dependent on randomization. Distal gastrectomy (subtotal/near total) was performed if there was a tumour-free margin of $5 \mathrm{~cm}$ beyond the proximal resection line. All other patients underwent total gastrectomy. Reconstruction of alimentary tract was performed according to the normal practice of our institution. For staging grouping, The New (2002) Tumour-Node-Metastasis (TNM) system classification was used. Time taken for each surgery was noted. Intra operative blood loss and need for any blood transfusion was noted.

Lymph node and histological staging was performed by a local pathologist and the results were reviewed by a panel of supervising pathologists. After the final pathological examination, the operation was classified as RO if the microscopical evidence indicated complete tumor free margins.

The postoperative course including all complications and reoperations was documented. In hospital mortality was defined as death within 30 days of the procedure or during the hospital stay. Adjuvant chemo radiotherapy was given to both D1 and modified D2 group with stage II, III and IV disease.

Patients undergoing both D1 and modified D2 resections were reviewed every 3 months for the first year and every 6 months thereafter. Endoscopy and CECT abdomen were arranged, if recurrent disease was suspected.

The patients were aged less than 80 years and in adequate physical condition with no serious comorbid cardio respiratory diseases that would preclude a safe modified D2/D1 lymphadenectomies. Patients were eligible for study if they had not undergone previous gastric surgery and had no coexisting cancer. All the patients were evaluated and assessed according to the proforma including an elaborate history, a detailed clinical examination, routine investigations and specific investigations. Diagnosis of all the patients was confirmed by endoscopic examination and histo-pathological examination of biopsy specimen taken. Preopoerative staging was done by CECT abdomen. After preoperative workup, patients underwent a staging laparotomy in order to exclude potentially non-curative cancer. Patients with stage IV disease were excluded from the study. Patients were randomized to undergo either D1 or modified D2 gastrectomy. In D1 resection, gastrectomy was done with removal of N1 group of lymphnodes and greater omentum; modified D2 resection included additional removal of N2 group of lymph nodes and omental bursa. D1 and modified D2 dissection were defined according to the guidelines of the Japanese Research Society for the study of gastric cancer. In these guidelines, 16 different lymph node compartments (stations) are identified surrounding the stomach. In general, the perigastric lymph node stations along the lesser (station 1, 3 and 5) and greater (station 2, 4 and 6) curvature are grouped N1, whereas the nodes along the left gastric (station 7), common hepatic (station 8), celiac (station 9) and splenic (station 10 and 11) arteries are grouped N2.

Splenopancreatectomy was not considered as a routine part of modified D2 gastrectomy; the spleen and pancreas were resected only when involved with tumour. The type of gastrectomy performed (distal/total) was not dependent on randomization. Distal gastrectomy (subtotal/near total) was performed if there was a tumour-free margin of $5 \mathrm{~cm}$ beyond the proximal resection line. All other patients underwent total gastrectomy. Reconstruction of alimentary tract was performed according to the normal practice of our institution. For staging grouping, The New (2002) Tumour-Node-Metastasis (TNM) system classification was used. Time taken for each surgery was noted. Intra operative blood loss and need for any blood transfusion was noted.

Lymph node and histological staging was performed by a local pathologist and the results were reviewed by a panel of supervising pathologists. After the final pathological examination, the operation was classified as RO if the microscopical evidence indicated complete tumor free margins.

The postoperative course including all complications and reoperations was documented. In hospital mortality was defined as death within 30 days of the procedure or during the hospital stay. Adjuvant chemo radiotherapy was given to both D1 and modified D2 group with stage II, III and IV disease.

Patients undergoing both D1 and modified D2 resections were reviewed every 3 months for the first year and every 6 months thereafter. Endoscopy and CECT abdomen were arranged, if recurrent disease was suspected. 


\section{Results and Observations}

Statistical software SPSS 16.0 was used to carry out the statistical analysis of data. Data was analysed by means of descriptive statistics viz, means, standard deviations and percentages. Student's independent t-test was employed for qualitative data. Chi-square test, Chi-square test with Yates correction and Fisher's exact test were used for qualitative data. A P-value of less than 0.05 was considered statistically significant.

1) Demographic Characteristics of studied patients: As depicted in Table 1, majority of the patients in both the groups were aged between 61 to 70 years and were male, unskilled by occupation and belonging to south Kashmir.

2) Presenting Symptoms of studied patients: Symptomatology in both the groups was similar with abdominal discomfort and early satiety being dominant symptoms as shown in Table 2.

3) Table 3: Clinical Examination in studied patients: Major sign in both the groups was pallor followed by abdominal lump, however there was no significant difference in clinical examination of both the groups as shown in Table 3.

4) Table 4: Comorbidity and ASA class in studied patients: Hypertension, diabetes mellitus and hypothyroidism were the major comorbidities in both the groups. Majority of the patients in both the groups belonged to ASA Class I. All the variables were non-significant.

5) Table 5: Preoperative Specific Investigations: Most of the patients in both the groups on EGD had ulcerative growths. Gastric outlet obstruction was seen in 13\% in D1 and 14.8\% in modified D2 groups. CECT showed stomach thickening and growth with perigastric lymphnodes in both the groups. All the variables were statistically insignificant.

Table 1. Demographic characteristics of studied patients.

\begin{tabular}{|c|c|c|c|c|c|c|}
\hline \multirow{2}{*}{\multicolumn{2}{|c|}{ Characteristics }} & \multicolumn{2}{|c|}{ D1 dissection } & \multicolumn{2}{|c|}{$\begin{array}{c}\text { Modified } \\
\text { D2 dissection }\end{array}$} & \multirow[t]{2}{*}{$p$ value } \\
\hline & & No. & $\%$ age & No. & $\%$ age & \\
\hline \multirow{4}{*}{ Age (Yr) } & $\leq 50$ & 2 & 8.7 & 3 & 11.1 & \multirow{3}{*}{0.574 (NS) } \\
\hline & $51-60$ & 8 & 34.8 & 10 & 37.0 & \\
\hline & $61-70$ & 13 & 56.5 & 14 & 51.9 & \\
\hline & Mean \pm SD & \multicolumn{2}{|c|}{$60.09 \pm 7.403$} & \multicolumn{2}{|c|}{$61.26 \pm 7.209$} & \\
\hline \multirow{2}{*}{ Gender } & Male & 18 & 78.3 & 20 & 74.1 & \multirow{2}{*}{0.729 (NS) } \\
\hline & Female & 5 & 21.7 & 7 & 25.9 & \\
\hline \multirow{2}{*}{ Occupation } & Unskilled & 16 & 69.6 & 19 & 70.4 & \multirow{2}{*}{0.164 (NS) } \\
\hline & Semiskilled & 7 & 30.4 & 8 & 29.6 & \\
\hline \multirow{3}{*}{ Residence } & South Kashmir & 13 & 56.5 & 17 & 63.0 & \multirow{3}{*}{0.556 (NS) } \\
\hline & Central Kashmir & 6 & 26.1 & 8 & 29.6 & \\
\hline & North Kashmir & 4 & 17.4 & 2 & 7.4 & \\
\hline
\end{tabular}

Table 2. Presenting symptoms of studied patients.

\begin{tabular}{|c|c|c|c|c|c|c|}
\hline & \multirow{2}{*}{ Symptoms } & \multicolumn{2}{|c|}{ D1 dissection } & \multicolumn{2}{|c|}{ Modified D2 dissection } & \multirow{2}{*}{ p value } \\
\hline & & No. & $\%$ age & No. & $\%$ age & \\
\hline \multirow{7}{*}{$\begin{array}{l}\text { Presenting } \\
\text { symptoms }\end{array}$} & Abdominal pain/Discomfort & 18 & 78.3 & 20 & 74.1 & 0.729 (NS) \\
\hline & Early satiety & 11 & 47.8 & 19 & 70.4 & 0.105 (NS) \\
\hline & Post prandial fullness & 15 & 65.2 & 18 & 66.7 & $0.914(\mathrm{NS})$ \\
\hline & Anorexia & 12 & 52.2 & 15 & 55.6 & $0.811(\mathrm{NS})$ \\
\hline & Dysphagia & 1 & 4.3 & 0 & 0.0 & $0.460(\mathrm{NS})$ \\
\hline & Haematemesis/Malena & 2 & 8.7 & 1 & 3.7 & $0.886(\mathrm{NS})$ \\
\hline & Weight loss & 16 & 69.6 & 21 & 77.8 & 0.509 (NS) \\
\hline
\end{tabular}


Table 3. Clinical examination in studied patients.

\begin{tabular}{ccccccc}
\hline \multirow{2}{*}{ Clinical examination } & \multicolumn{2}{c}{ D1 dissection } & \multicolumn{2}{c}{$\begin{array}{c}\text { Modified } \\
\text { D2 dissection }\end{array}$} & p value \\
\cline { 2 - 6 } & & No. & \% age & No. & \% age & \\
\hline & Pallor & 10 & 43.5 & 8 & 29.6 & 0.309 (NS) \\
Jaundice & 0 & 0.0 & 0 & 0.0 & 1.000 (NS) \\
General physical & Oedema & 0 & 0.0 & 1 & 3.7 & 1.000 (NS) \\
examination & Lymphadenopathy & 0 & 0.0 & 0 & 0.0 & 1.000 (NS) \\
& Chest abnormality & 0 & 0.0 & 0 & 0.0 & 1.000 (NS) \\
& CVS abnormality & 0 & 0.0 & 0 & 0.0 & 1.000 (NS) \\
Abdominal & Abdominal lump & 1 & 4.3 & 2 & 7.4 & 0.649 (NS) \\
examination & Ascites & 0 & 0.0 & 0 & 0.0 & 1.000 (NS) \\
\hline
\end{tabular}

Table 4. Co-morbidity and ASA class in studied patients.

\begin{tabular}{|c|c|c|c|c|c|c|}
\hline \multirow{2}{*}{\multicolumn{2}{|c|}{ Co-morbidities }} & \multicolumn{2}{|c|}{ D1 dissection } & \multicolumn{2}{|c|}{$\begin{array}{c}\text { Modified } \\
\text { D2 dissection }\end{array}$} & \multirow{2}{*}{$p$ value } \\
\hline & & No. & $\%$ age & No. & $\%$ age & \\
\hline \multicolumn{2}{|c|}{ No-morbidities } & 10 & 43.5 & 15 & 55.6 & 0.570 (NS) \\
\hline \multirow{3}{*}{ Type of co-morbidity } & Diabetes mellitus & 2 & 8.7 & 2 & 7.4 & \\
\hline & Hypertension & 7 & 30.4 & 9 & 33.3 & 0.365 (NS) \\
\hline & Hypothyroidism & 4 & 17.4 & 1 & 3.7 & \\
\hline \multirow{3}{*}{ ASA } & Class I & 15 & 65.2 & 18 & 66.7 & \\
\hline & Class II & 6 & 26.1 & 8 & 29.6 & 0.750 (NS) \\
\hline & Class III & 2 & 8.7 & 1 & 3.7 & \\
\hline
\end{tabular}

Table 5. Preoperative specific investigations.

\begin{tabular}{|c|c|c|c|c|c|c|}
\hline \multicolumn{2}{|c|}{ Investigations } & \multicolumn{2}{|c|}{ D1 dissection } & \multicolumn{2}{|c|}{$\begin{array}{c}\text { Modified } \\
\text { D2 dissection }\end{array}$} & \multirow[t]{2}{*}{ p value } \\
\hline & & No. & $\%$ age & No. & $\%$ age & \\
\hline \multirow{6}{*}{$\begin{array}{l}\text { Esophagogastro-duodenoscopy } \\
\text { (EGD) }\end{array}$} & Abdominal lump & 1 & 4.3 & 2 & 7.4 & 0.649 (NS) \\
\hline & $\begin{array}{l}\text { Ulcerative lesion in } \\
\text { stomach }\end{array}$ & 20 & 87.0 & 22 & 81.5 & \multirow{5}{*}{0.687 (NS) } \\
\hline & $\begin{array}{l}\text { Polypoid growth in } \\
\text { stomach }\end{array}$ & 10 & 43.5 & 17 & 63.0 & \\
\hline & $\begin{array}{c}\text { Gastric outlet } \\
\text { obstruction }\end{array}$ & 3 & 13.0 & 4 & 14.8 & \\
\hline & Stomach thickening & 20 & 87.0 & 22 & 81.5 & \\
\hline & Stomach growth & 17 & 73.9 & 19 & 70.4 & \\
\hline \multirow[t]{2}{*}{ CECT abdomen } & $\begin{array}{l}\text { Perigastric lymph } \\
\text { nodes }\end{array}$ & 15 & 65.2 & 20 & 74.1 & \multirow[t]{2}{*}{0.827 (NS) } \\
\hline & N2 lymph nodes & 1 & 4.3 & 3 & 11.1 & \\
\hline
\end{tabular}

6) Table 6: Types of Procedure and Reconstruction: Majority of patients in both groups had undergone subtotal gastrectomy and Bilroth II was the main reconstructive modality. Both these variables were insignificant.

7) Table 7: Operative Findings in the patients and Tumour Stage: Ulcerative growth with perigastric lymphnodes was the major intraoperative finding in both the groups.

T2 stage was seen in $43.5 \%$ and $29.6 \%$ of cases in D1 and modified D2 groups respectively and T3 stage was seen in $34.8 \%$ and $44.4 \%$ of cases in D1 and modified D2 groups respectively. All variables were insignificant.

8) Table 8: Blood Transfusions in the patients and durations of surgery: Intraoperative blood transfusion was 
Table 6. Types of procedure and reconstruction.

\begin{tabular}{|c|c|c|c|c|c|c|}
\hline \multicolumn{2}{|c|}{ Procedure and Reconstruction } & \multicolumn{2}{|c|}{ D1 dissection } & \multicolumn{2}{|c|}{$\begin{array}{c}\text { Modified } \\
\text { D2 dissection }\end{array}$} & \multirow{2}{*}{ p value } \\
\hline & & No. & $\%$ age & No. & $\%$ age & \\
\hline \multirow{6}{*}{ Procedure } & Total gastrectomy & 3 & 13.0 & 5 & 18.5 & \multirow{6}{*}{0.772 (NS) } \\
\hline & Near total gastrectomy & 5 & 21.7 & 7 & 25.9 & \\
\hline & Subtotal gastrectomy & 15 & 65.2 & 15 & 55.6 & \\
\hline & $\begin{array}{l}\text { Total gastrectomy } \\
\text { With splenectomy }\end{array}$ & 0 & 0.0 & 0 & 0.0 & \\
\hline & $\begin{array}{l}\text { Near total gastrectomy } \\
\text { With splenectomy }\end{array}$ & 0 & 0.0 & 0 & 0.0 & \\
\hline & $\begin{array}{l}\text { Subtotal gastrectomy } \\
\text { With transverse colectomy }\end{array}$ & 0 & 0.0 & 0 & 0.0 & \\
\hline \multirow{2}{*}{$\begin{array}{c}\text { Type of } \\
\text { reconstruction }\end{array}$} & Bilroth II & 21 & 91.3 & 23 & 85.2 & \multirow{2}{*}{0.820 (NS) } \\
\hline & Roux-en-Y & 2 & 8.7 & 4 & 14.8 & \\
\hline
\end{tabular}

Table 7. Operative findings in the patients and tumour stage.

\begin{tabular}{|c|c|c|c|c|c|c|}
\hline & \multirow{2}{*}{ Findings } & \multicolumn{2}{|c|}{ D1 dissection } & \multicolumn{2}{|c|}{$\begin{array}{c}\text { Modified } \\
\text { D2 dissection }\end{array}$} & \multirow{2}{*}{ p value } \\
\hline & & No. & $\%$ age & No. & $\%$ age & \\
\hline \multirow{5}{*}{ Operative findings } & $\begin{array}{l}\text { Ulcerative growth in } \\
\text { stomach }\end{array}$ & 5 & 21.7 & 2 & 7.4 & \multirow{5}{*}{0.471 (NS) } \\
\hline & Polypoid growth in stomach & 3 & 13.0 & 3 & 11.1 & \\
\hline & $\begin{array}{l}\text { Ulcerative growth in } \\
\text { stomach with perigastric } \\
\text { lymphadenopathy }\end{array}$ & 8 & 34.8 & 15 & 55.6 & \\
\hline & $\begin{array}{l}\text { Polypoid growth in } \\
\text { stomach with perigastric } \\
\text { lymphadenopathy }\end{array}$ & 5 & 21.7 & 6 & 22.2 & \\
\hline & $\begin{array}{l}\text { Stenosing growth in pylorus } \\
\text { causing obstruction }\end{array}$ & 2 & 8.7 & 1 & 3.7 & \\
\hline \multirow{4}{*}{ Tumour stage } & $\mathrm{T} 1$ & 4 & 17.4 & 6 & 22.2 & \multirow{4}{*}{0.775 (NS) } \\
\hline & $\mathrm{T} 2$ & 10 & 43.5 & 8 & 29.6 & \\
\hline & T3 & 8 & 34.8 & 12 & 44.4 & \\
\hline & $\mathrm{T} 4$ & 1 & 4.3 & 1 & 3.7 & \\
\hline
\end{tabular}

Table 8. Blood transfusions in the patients and durations of surgery.

\begin{tabular}{|c|c|c|c|c|c|c|}
\hline \multirow{2}{*}{\multicolumn{2}{|c|}{ Blood transfusions }} & \multicolumn{2}{|c|}{ D1 dissection } & \multicolumn{2}{|c|}{$\begin{array}{c}\text { Modified } \\
\text { D2 dissection }\end{array}$} & \multirow[t]{2}{*}{$P$ value } \\
\hline & & No. & $\%$ age & No. & $\%$ age & \\
\hline \multirow{3}{*}{$\begin{array}{l}\text { Pre-op blood } \\
\text { transfusion }\end{array}$} & None & 18 & 78.3 & 17 & 63.0 & \multirow{3}{*}{0.501 (NS) } \\
\hline & One & 3 & 13.0 & 6 & 22.2 & \\
\hline & Two & 2 & 8.7 & 4 & 14.8 & \\
\hline \multirow{2}{*}{$\begin{array}{l}\text { Intra-op blood } \\
\text { transfusion }\end{array}$} & None & 20 & 87.0 & 10 & 37.0 & \multirow{2}{*}{0.001 (Sig) } \\
\hline & One & 3 & 13.0 & 17 & 63.0 & \\
\hline \multirow{2}{*}{$\begin{array}{l}\text { Post-op blood } \\
\text { transfusion }\end{array}$} & None & 19 & 82.6 & 16 & 59.3 & \multirow{2}{*}{0.137 (NS) } \\
\hline & One & 4 & 17.4 & 11 & 40.7 & \\
\hline $\begin{array}{l}\text { Volume of Blood } \\
\text { Loss (ml) }\end{array}$ & $($ Mean \pm SD) & \multicolumn{2}{|c|}{$700.78 \pm 47.945$} & \multicolumn{2}{|c|}{$880.11 \pm 64.785$} & $<0.001$ (Sig) \\
\hline $\begin{array}{c}\text { Duration of Surgery } \\
\text { (Minute) }\end{array}$ & $($ Mean \pm SD) & \multicolumn{2}{|c|}{$168.87 \pm 17.03$} & \multicolumn{2}{|c|}{$288 \pm 20.094$} & $<0.001$ (Sig) \\
\hline
\end{tabular}


needed in 17 (63\%) patients in modified D2 group as opposed to only 3 patients (13\%) requiring it in D1 group. This finding was statistically significant with p value of 0.001 .

Mean volume of blood loss in D1 group was $700.747 .9 \mathrm{ml}$ and in modified D2 group it was $880.11+64.74$ $\mathrm{ml}$. This was also statistically significant with a p value of $<0.001$.

Mean duration of surgery in D1 group was 168.817 .03 minutes and in modified D2 group it was $288.00+$ 20.09 minutes. The result was statistically significant with a p value of $<0.001$.

9) Table 9: Postoperative Complications and Hospital mortality: In the table, 11 patients in both the groups experienced postoperative complications which were common to both groups like postoperative GI bleeding, anastomic site leak, wound infection etc. 6 patients in D1 group had In-hospital mortality as opposed to 1 patient who died in hospital in modified D2 group. This was statistically significant with a p value of 0.038 .

10) Table 10: Pathological Characteristics of the Studied Patients: Most of the patients of both the groups had papillary adeno-carcinoma as the dominant histology. However in D1 next most common histology was mucinous adenocarcinoma (21.7\%), whereas in modified D2 next most common histologic variant was signet ring adenocarcinoma (14.8\%). In D1, 2 patients (8.7\%) had stage I disease, 10 patients (43.5\%) had stage II disease and 11 patients (47.8\%) had stage III disease, whereas in modified D2 4 patients (14.8\%) had stage I disease, 13 patients (48.1\%) had stage II disease while as 9 patients (33.3\%) had stage III disease. All of the variables

Table 9. Postoperative complications and hospital mortality.

\begin{tabular}{|c|c|c|c|c|c|}
\hline \multirow{2}{*}{ Postoperative complications } & \multicolumn{2}{|c|}{ D1 dissection } & \multicolumn{2}{|c|}{$\begin{array}{c}\text { Modified } \\
\text { D2 dissection }\end{array}$} & \multirow[t]{2}{*}{ p value } \\
\hline & No. & $\%$ age & No. & $\%$ age & \\
\hline Haemorrhage & 2 & 8.7 & 3 & 11.1 & 0.776 (NS) \\
\hline Anastamotic leak & 2 & 8.7 & 1 & 3.7 & $0.886(\mathrm{NS})$ \\
\hline Wound infection & 3 & 13.0 & 1 & 3.7 & 0.490 (NS) \\
\hline Respiratory sepsis & 2 & 8.7 & 2 & 7.4 & 1.000 (NS) \\
\hline Subphrenic collection & 1 & 4.3 & 2 & 7.4 & 0.649 (NS) \\
\hline Myocardial infarction & 1 & 4.3 & 0 & 0.0 & 0.460 (NS) \\
\hline Persistent drainage (>8 days) & 0 & 0.0 & 2 & 7.4 & 0.493 (NS) \\
\hline In-hospital mortality & 6 & 26.0 & 1 & 3.7 & 0.038 (Sig) \\
\hline
\end{tabular}

Table 10. Pathological characteristics of the studied patients.

\begin{tabular}{|c|c|c|c|c|c|c|}
\hline \multirow{2}{*}{\multicolumn{2}{|c|}{ Pathological characteristics }} & \multicolumn{2}{|c|}{ D1 dissection } & \multicolumn{2}{|c|}{$\begin{array}{c}\text { Modified } \\
\text { D2 dissection }\end{array}$} & \multirow{2}{*}{ p value } \\
\hline & & No. & $\%$ age & No. & $\%$ age & \\
\hline \multirow{4}{*}{$\begin{array}{l}\text { Morphology of } \\
\text { tumour }\end{array}$} & papillary adenocarcinoma & 15 & 65.2 & 18 & 66.7 & \multirow{4}{*}{0.163 (NS) } \\
\hline & Tubular adenocarcinoma & 1 & 4.3 & 4 & 14.8 & \\
\hline & $\begin{array}{c}\text { Mucinous } \\
\text { adenocarcinoma }\end{array}$ & 5 & 21.7 & 1 & 3.7 & \\
\hline & $\begin{array}{c}\text { Signet ring } \\
\text { adenocarcinoma }\end{array}$ & 2 & 8.7 & 4 & 14.8 & \\
\hline \multirow{4}{*}{ Stage of disease } & I & 2 & 8.7 & 5 & 18.5 & \multirow{4}{*}{$0.531(\mathrm{NS})$} \\
\hline & II & 10 & 43.5 & 13 & 48.1 & \\
\hline & IIIA & 8 & 34.8 & 5 & 18.5 & \\
\hline & IIIB & 3 & 13.0 & 4 & 14.8 & \\
\hline \multicolumn{2}{|c|}{ Surgical margins free (RO) } & 23 & 100.0 & 27 & 100.0 & 1.000 (NS) \\
\hline \multicolumn{2}{|c|}{ Number of dissected lymph nodes (median) } & \multicolumn{2}{|c|}{$9(3-23)$} & \multicolumn{2}{|c|}{$23(15-42)$} & $<0.001$ (Sig.) \\
\hline \multirow{3}{*}{ N Staging } & NO & 7 & 30.4 & 6 & 22.2 & \multirow{3}{*}{0.173 (NS) } \\
\hline & $\mathrm{N} 1$ & 10 & 43.5 & 7 & 25.9 & \\
\hline & $\mathrm{N} 2$ & 6 & 26.1 & 14 & 51.9 & \\
\hline
\end{tabular}


were statistically insignificant. Both the groups had surgical tumour free resection margins $\left(\mathrm{R}_{0}\right)$, thus making the difference insignificant. The median number of lymph nodes dissected in D1 group was 9 and in modified D2 group it was 23. This difference was statistically significant $(\mathrm{p}<0.001)$.

11) Table 11: AdJuvant Chemo radiotherpy used in patients: All patients with stage II and stage III of both the groups received adjuvant chemo radiation. This was statistically insignificant.

12) Table 12: Outcome of patients and recurrence of disease In-hospital mortality in D1 was $26.1 \%$ whereas it was only $3.7 \%$ in modified D2 making the variable significant. Recurrence in D1 was $26.1 \%$ and no recurrence has occurred in modified D2, again making this variable significant. Out of 6 recurrences in D1, all 6 had recurrences at anastomatic site, additionally 1 patient had enlarged lymphnodes at porta hepatis, another 1 had liver metastasis and other 2 had peritoneal metastasis. No further deaths were observed in both the groups in the follow up period.

\section{Discussion}

Opinion over the optimum resection for patients with gastric cancer remains divided, and the literature polarized. The impressive outcomes after modified D2 gastrectomy published in large retrospective series from Japan (Soga et al., 1979 and Maruyama et al., 1987) [5] [6] have not been reproduced in randomized comparative studies from Europe (Bonenkamp et al., 1995, 1999; Cushieri et al., 1996, 1999) [7] [8]. The two largest randomized studies both report significantly greater operative morbidity and mortality associated with extended D2 lymphadenectomy when compared to less aggressive D1 lymphadenectomy, and have failed to demonstrate any survival advantage for a modified D2 resection. Many of the serious complications associated with D2 resection were associated with resections of pancreas and spleen (Bonenkamp et al., 1995; Cushieri et al., 1999) [7] [8]. Although this latter report concluded that a classical D2 resection offered no survival advantage over a D1 resection, the possibility that a modified D2 resection, preserving pancreas and spleen might be better than a D1 resection was not dismissed (Cushieri et al., 1999) [8].

The first report of outcomes after modified D2 gastrectomy for gastric cancer were originally published in Britain by Sue-Ling et al., 1993 [9] and subsequently Griffith et al. (1995) [10]. Despite these favourable reports, there remains a widely held assumption, that poor outcomes after surgery for gastric cancer in Britain are due to greater age, comorbidity, advanced stage of disease and greater body mass indices of western patients when compared to with these Japanese counterparts.

Table 11. AdJuvant chemo radiotherapy used in patients.

\begin{tabular}{ccccc}
\hline & \multicolumn{2}{c}{ D1 dissection } & \multicolumn{2}{c}{ Modified D2 dissection } \\
\cline { 2 - 5 } & No. & \% age & No. & \% age \\
\hline Adjuvant chemo radiation & 20 & 87.0 & 22 & 81.5 \\
\hline
\end{tabular}

Table 12. Outcome of patients and recurrence of disease.

\begin{tabular}{|c|c|c|c|c|c|c|}
\hline \multirow{2}{*}{ Characteristics } & & \multicolumn{2}{|l|}{ D1 } & \multicolumn{2}{|l|}{ D2 } & \multirow{2}{*}{$p$ value } \\
\hline & & No. & $\%$ age & No. & $\%$ age & \\
\hline \multirow{2}{*}{ Outcome at discharge } & Surviving & 17 & 73.9 & 26 & 96.3 & \multirow{2}{*}{0.0386 (Sig) } \\
\hline & Died & 6 & 26.1 & 1 & 3.7 & \\
\hline Recurrence of disease & & 6 & 26.1 & 0 & 0.0 & 0.037 (Sig) \\
\hline \multirow{3}{*}{ Follow up CECT abdomen } & $\begin{array}{l}\text { Enlarged lymph nodes at } \\
\text { porta hepatis }\end{array}$ & 1 & 4.3 & 0 & 0.0 & \multirow{3}{*}{0.038 (Sig) } \\
\hline & Peritoneal metastasis & 2 & 8.7 & 0 & 0.0 & \\
\hline & Liver metastasis & 1 & 4.3 & 0 & 0.0 & \\
\hline $\begin{array}{l}\text { Esophagogastro-dudenoscopy } \\
\text { (EGD) at follow up }\end{array}$ & Recurrence at anastamosis & 6 & 26.1 & 1 & 3.7 & 0.0386 (Sig) \\
\hline Outcome at follow up & Surviving & 17 & 100.0 & 26 & 100.0 & 1.000 (NS) \\
\hline
\end{tabular}


Recently, 15 year follow up results of a randomized nationwide Dutch D1 modified D2 trial were reported. The overall 15-year survival was 21\% (82 patients) for the D1 group and 29\% (92 patients) for the modified D2 group $(\mathrm{p}=0.34)$. The gastric-cancer related death rate was significantly higher in the $\mathrm{D} 1$ group $(48 \%, 182 \mathrm{pa}-$ tients) compared with that in the modified D2 group (37\%, 123 patients), whereas death due to other diseases was similar in both groups [11]. The authors indicated in the interpretation that because a safer, spleen-preserving modified D2 resection technique had become available in high-volume centres, modified D2 lymphadenectomy should be the recommended surgical approach for patients with resectable (curable) gastric cancer. The Italian Gastric Cancer Study Group (IGCSG) has shown the safety of modified D2 dissection with pancreas preservation in a one-arm phase I-II trial [12]. Between 1994 and 1996, 191 eligible patients were entered in the study. The overall morbidity rate was $20.9 \%$. Surgical complications were observed in $16.7 \%$ of patients and reoperation was necessary in six patients and was successful in all cases. The overall hospital mortality rate was $3.1 \%$; it was higher after total gastrectomy (7.46\%) than after distal gastrectomy (0.8\%). This study concluded that postoperative morbidity and mortality rates were favourable comparable to those reported after the standard Western gastrectomy and that the more extensive Japanese procedure with pancreas preservation can be regarded as a safe radical treatment for gastric cancer in selected Western patients treated at experienced centres. Another single-institutional small-scale RCT has reported from Taiwan that there were no significant differences in the postoperative and mortality between patients undergoing modified D2 and D1 gastrectomy [13] [14]. This was the only trial that showed a significantly higher 5-year disease-specific survival in patients with modified D2 surgery than in those with D1 surgery. Therefore, modified D2 gastrectomy is becoming accepted as a safe treatment for gastric cancer at experienced centres, in Western countries.

In our state, gastric cancer presents as one of the most difficult problems for surgeons because the majority of the patients have advanced disease at presentation. Most of the tumours in our patients are T3 and N2 lymph nodes are usually involved. Therefore dissection of perigastric N1 nodes only (D1 dissection) seems to be inadequate. So the aim of our study was to compare D1 with modified D2 gastrectomy in terms of morbidity, mortality and recurrence.

The two groups in our study were fit for such a study, because there were no statistically significant differences regarding the demographic profile, clinical, laboratory, and radiological parameters amongst the two groups. There were also no significant differences in the endoscopic features, histopathology or the initial tumour stage in the two groups.

Our study was conducted on 50 patients (23 D1 and 27 modified D2 group) who were admitted, investigated and operated in the Postgraduate Department of the General Surgery, Government Medical College, Srinagar.

Most common age group suffering from the disease in our study was $61-70$ years in both the groups with a mean of 60.09 years in D1 and 61.26 years in modified D2 group. Almost similar observations were made by M. Degiuli et al., 2014 (63 in D1 and 61 in modified D2) [15] and H. Danielson et al., 2007 (66 in D1 and 60 in modified D2) [16]. Among the D1 group 78.3 percent were males and 21.7 percent were females, and in modified D2 group 74.1 percent were males and 25.9 percent were females. Similar observations were made by W. G. Lewis et al., 2002 (70:30 in D1 and 74:26 in modified D2) [17] and P. Edwards et al., 2004 (58:42 in D1 and 70:30 in modified D2) [18]. Most of the patients in our study belonged to rural areas amongst whom 69.6 percent in D1 and 70.4 percent in modified D2 were unskilled (mostly farmers). High incidence of disease was confirmed by Strong et al. in Cost Rica, in the Japanese farmers [19]. Excessive use of nitrate fertilizers (and hence exposure to nitrates) could be a possible explanation. Also majority of population in our world are farmers.

Clinical signs and symptoms were almost same among the two groups. Abdominal discomfort was the most common presenting symptom present in 74.1 percent in modified D2 and 78.3 percent in D1 group. Early satiety was the second most common symptom which was present in 47.8 percent in D1 and 70.4 percent in modified D2 group. Other common symptoms which were present in both groups are; post prandial fullness, anorexia, and weight loss. Pallor was present in 43.5 percent patients in D1 and 29.6 percent in modified D2 group. Similar results have been observed by Wanebo H. J. et al., 1993 [20].

Haemoglobin ranged from $9-14 \mathrm{gm} / \mathrm{dl}$ (mean $11.5+1.2)$ in D1 group and $10-13 \mathrm{gm} / \mathrm{dl}$ (mean $12.19+1.1$ ) in the modified D2 group. Other laboratory parameters like TLC, DLC, KFT, LFT were within normal limits and comparable in both groups.

56.5 percent of patients in D1 group had co morbidities like hypertension, diabetes mellitus and hypothyroidism, while as 44.4 percent patients in modified D2 group had similar type of co morbidities. Most of the patients 
in both the groups were ASA I and ASA II class. Similar reports of ASA class have been shown by W. G. Lewis et al., 2002 (ASA I: 14\% in D1 and 4\% in modified D2, ASA II: 56\% in D1 and 51\% in modified D2, ASA III: $20 \%$ in D1 and $40 \%$ in modified D2) [17].

In the present study, patients were evaluated by esophagogastro-duodenoscopy. In both groups ulcerative type of stomach growth was more common than polypoid growth. Small number of patients in both the groups had gastric outlet obstruction. About 78.3 percent of patients in D1 and 70.4 percent in modified D2 group had tumour in distal stomach. Cardia was involved in 10 percent of patients in D1 and 8.7 percent of patients in modified D2 group. 7.4 percent of patients had growth in the mid body of stomach in D1 group and in 22 percent in modified D2 group. This finding was supported by M. Degiuli et al., 2014. They found that distal tumours were seen in 65\% in D1 and 67\% in modified D2 group, mid body tumours in 24\% in D1 and 22\% in modified D2 group and proximal tumours in 9\% in D1 and 9.7\% in modified D2 group. Chang-Ming Huang et al. in 2011 showed that $80 \%$ of tumours in stomach involve distal part, 115 in mid body, rest are proximal tumours [21].

CECT abdomen was used in preoperative staging of carcinoma stomach patients. Only the stomach thickening was seen in 87 percent patients in D1 and 81.5 percent in modified D2 group. Infiltrating stomach growth was seen in 73.9 percent in D1 and 70.4 percent in modified D2. Perigastric lymph nodes were enlarged in 18 percent in both the groups. Only one patient had N2 lymph node involvement. Data related to the CT findings has not been mentioned in previous series. However there were no statistically significant differences among the two study groups with regards to the CT findings.

Subtotal gastrectomy was performed in all patients with distal tumours (65.2 percent in D1 and 55.6 percent in modified D2). Near total gastrectomy was performed in mid body tumours (D1 21.7 percent and in modified D2 25.9 percent) and total gastrectomy was performed in proximal tumours in both the groups (13 percent in D1 and 18.5 percent in modified D2 group). A proximal resection margin of $6-7 \mathrm{~cm}$ was always taken. After total gastrectomy Roux-en Y reconstruction was performed and after subtotal gastrectomy Bilroth II reconstruction was done.

These observations are supported by the findings seen by M. Degiuli et al., 2014 who undertook a randomized controlled trial in Western centres to compare D1 and modified D2 gastrectomy. Total gastrectomy was performed 26 percent in D1 patients and 23 percent in modified D2 patients. They performed subtotal gastrectomy in 73 percent in D1 and in 76 percent in modified D2 patients. Type of reconstruction was also similar as in our study; Roux en Y after total gastrectomy and Bilroth II after subtotal gastrectomy [15]. Also P. Edwards et al., 2004 showed similar results [18].

As most of the patients with carcinoma stomach in our valley have advanced disease at presentation. In operative findings, 34.8 percent in D1 group and 44.4 percent in modified D2 group had T3 lesions in stomach (breaching serosa). 4.3 percent in D1 and 3.7 percent in modified D2 group had T4 lesion, T2 lesion was present in 43.5 percent in D1 and 29.6 percent in modified D2 group and T1 lesion was seen in 17.4 percent in D1 and 22.2 percent in modified D2 group. Similar results have been shown by Cushieri et al., 1999 [8]. They have shown 43\% of patients in D1 and 44\% in modified D2 having T3 lesions, T2 lesions in 32\% in D1 and 35\% in modified D2 group. M. Degiuli et al., 2014 showed T1, T2 and T3 lesions in D1 patients with an almost equal frequency of 36\%, 31\% and 30\% respectively and in modified D2 group as 29\%, 41\% and 27\% respectively [15].

In the present study, the mean operative blood loss in D1 gastrectomy was $700.7 \mathrm{ml}$ while in modified D2 gastrectomy it was $880.1 \mathrm{ml}(\mathrm{p}<0.001)$, which was significant. Mean duration of surgery in D1 group was 168.87 minutes, in modified D2 group it was 288.01 minutes $(p<0.001$ ), again this was statistically significant. 13 percent of patients in D1 group and 63 percent in modified D2 group required intra operative blood transfusion, ( $\mathrm{p}<0.001)$ which was quite significant.

Since modified D2 gastrectomy requires dissection of N2 level of lymph nodes which are along major vessels like splenic artery, celiac artery. Dissection of these lymph nodes is done very carefully and meticulously, that is the reason for greater amount of blood loss and more duration of surgery in modified D2 gastrectomy than D1 gastrectomy.

Almost similar results have been shown by H. Danielson et al., 2007 in their study; median blood loss in D1 patients was $800 \mathrm{ml}$, while as it was $1200 \mathrm{ml}$ in modified D2 group ( $<0.001$ ). The median operation time in modified D2 operations was 274 minutes while as it was 204 minutes in D1 gastrectomy $(p<0.000)$ [16]. Our results were slightly different from the study of Asada Methasate et al., 2010 who has shown a mean blood loss of $448 \mathrm{ml}$ in modified D2 gastrectomy and mean operative time of 238 minutes in modified D2 gastrectomy, 
both of which were less than in our study [22].

Overall, the rate of complications after modified D2 dissection was much lower in our study than that in European series and close to those reported from Japanese reference centres [8].

The rate of anastamotic leakage was low in the present study, with only two leaks in both D1 and 1 leak in modified D2 groups, with no duodenal stump leak in either group.

Only 9 (38 percent) patients out of 23 in D1 group and 10 (27 percent) patients out of 27 in modified D2 group developed operative complications in the form of wound infections (13 percent in D1 and 3.7 percent in modified D2), respiratory sepsis (8.7 percent in D1 and 7.4 percent in modified D2 group), subphrenic collection (4.3 percent in D1 and 7.4 percent in modified D2) and haemorrhage (8.7 percent in D1 and 11.1 percent in modified D2 group). One complication specific to modified D2 resection was persistent drainage of serous fluid because of extensive lymphadenectomy. There was no significant difference in the postoperative morbidity in the two groups of patients.

More than 75 percent of cancers in the present study were distal and only 15 to 25 percent were proximal gastric cancers. Consequently total gastrectomy was performed in only one quarter of patients. As distal gastrectomy is reported to have fewer complications and reduced mortality compared with total gastrectomy, this and avoidance of routine spleno-pancreatectomy during the modified D2 gastrectomy, may partly explain the low morbidity.

Similar morbidity rates have been reported by P. Edwards et al., 2004 with 25\% morbidity in D1 and 23\% in modified D2 gastrectomy with anastamotic leaks, respiratory sepsis, subphrenic collections and thromboembolism as major morbidity in both groups [18]. H. Danielson et al., 2007 in their study found 33\% morbidity in D1 and $48 \%$ in modified D2 group, which is quite high than in our study [16]. Another study conducted by W. G. Lewis et al., 2002 have shown 36\% morbidity in D1 gastrectomy and 28\% in modified D2 group, which is again higher than our results [17].

Mortality rates associated with radical resection of stomach cancer have improved greatly owing to more rigorous patient selection and development in the surgical techniques and postoperative care [23] [24]. In the present study, the in-hospital mortality rate was 13 percent in both D1 and 3.7 percent in modified D2 gastrectomies ( $\mathrm{p}<0.038$ ). None of the patient who died after a modified D2 gastrectomy had undergone a splenectomy or pancreatectomy. In D1 group one patient died with sepsis because of anastamotic leak, second died with respiratory sepsis in post operative period and third patient died because of postoperative myocardial infarction, fourth patient died because of pulmonary thromboembolism, fifth died because of electrolyte imbalances and associated cardiac arrhythmias and the sixth patient died because of sudden cardiorespiratory arrest. In modified D2 group the only patient died with haemorrhage.

Similar moratlity rates have been seen by P. Edwards et al., 2004 with a mortality rate of 8.3\% in D1 gastrectomy and 7.3\% in modified D2 gastrectomy patients in their study [18]. J. J. Bonenkamp et al., 1999, in their study have shown a mortality rate of $4 \%$ in D1 group and 10\% in modified D2 patients [7]. Another study conducted by H. Danielson et al., 2007 to compare D1 versus modified D2 gastrectomy, had a mortality rate of 1.8\% in D1 group and 3.7\% in modified D2 group, which was comparable to our results [16]. Cushieri et al., 1996 have shown mortality rate of 6.5\% in D1 gastrectomy patients and 13\% for modified D2 group [25].

The mean hospital stay in the present study for D1 patients was 14 days and for modified D2 patients it was 14.11 days. Mean post operative stay was 7.6 days in D1 group and 7.9 days for modified D2 group. Both were statistically insignificant $(\mathrm{p}<0.200)$.

Similar results have been found by J. J. Bonenkamp et al., 1999. In their study mean hospital stay for D1 patients was 14 days and for modified D2 patient it was 16 days. H. Danielson et al., 2007 (11 days for D1 and 12 days for modified D2 patients) also support our results [16].

In our patients, on histopathological examination of tumour, papillary adenocarcinoma was seen in 65.2 percent in D1 and 66 percent in modified D2 group, tubular adenocarcinoma in 4.3 percent in D1 and 14.8 percent in modified D2 group, mucinous adenocarcinoma in 21.7 percent in D1 and 3.7 percent in modified D2 group and signet ring adenocarcinoma in 8.7 percent in D1 and 14.8 percent in modified D2 group. About $90 \%$ of tumours in our study were differentiated carcinomas.

This finding was contradictory to Chang Ming Huang et al., 2011 (differentiated growths $=22.1 \%$ and undifferentiated $=77.9 \%)[21]$ and Asada Methasate et al., 2010 (differentiated $=40 \%$ and undifferentiated $=60 \%$ ) [22]. 
In present study, stage I disease was seen in 8.7 percent in D1 and 18.5 percent in modified D2 group, stage II was seen in 43.5 percent in D1 and 48.1 percent in modified D2 group, stage IIIA was seen in 34.8 percent in D1 and 18.5 percent in modified D2 group and stage IIIB in 13.1 percent in D1 and 14.8 percent in modified D2 patients.

Almost similar findings were obtained by P. Edwards et al., 2004 (stage I-D1 $=33 \%$, modified D2 $=20 \%$, stage II-D1 $=25 \%$, modified D2 $=28 \%$, stage IIIA-D1 $=33 \%$, modified D2 $=23 \%$, and stage IIIB-D1 $=8 \%$, modified D2 $=29 \%$ ) [18]. Cushieri et al., 1999 has shown most of their patients had stage III disease in both the groups, while as in our study most of the patients had stage II disease in both categories [8]. M. Degiuli et al., 2014 have shown that 45\% patients in D1 group had stage I disease and 41\% in modified D2 had stage I disease. While as in our study only 10\% patients had stage I disease in D1 and 6\% in modified D2 group [15].

The median number of lymph nodes dissected in D1 group in our study was 9 (range 3 - 23) and in modified D2 23 (range 15 - 42). Similar findings were obtained by J. J. Bonenkamp et al., 1999 (D1 = 17 and modified D2 = 30) [7] and Cushieri et al., 1999 (D1 = 13 lymph nodes and modified D2 = 17) [8]. Our yield of lymph nodes dissected out was less than M. Degiuli et al., 2014 (D1 = 28 and modified D2 = 37) [15], and more than P. Edwards et al., 2004 (D1-8 and modified D2-15) [18]. After discharge from hospital every patient was followed as per follow up protocol. At follow up symptoms and signs were noted and routine investigations done. Most of the patients had generalized weakness as their complaint and pallor was present in most of patients in both the categories. Mean haemoglobin at follow up in both groups was $9 \mathrm{gm} / \mathrm{dl}$.

About 87 percent patients in D1 group received adjuvant chemo radiation and 81.5 percent in modified D2 received adjuvant chemo radiation. Mean follow up period was 13.1 months in D1 and 14.2 months in modified D2 patients at follow up if recurrent disease was suspected in any patient, urgent EGD and CECT abdomen was done. Out of 23 patients in D1 group, 6 patients developed recurrence. EGD detected anastamotic recurrence in all 6 patients. CECT abdomen was done which was normal. 4 patients were re-operated; total gastrectomy with Roux-En-Y reconstruction was done. Patient is doing well and is following us. 4 recurrences were detected on CECT abdomen and these patients had stage IV disease; 2 patients had developed peritoneal metastasis and malignant ascites, one had enlarged lymph nodes at porta hepatis and another had diffuse liver metastasis.

Out of 6 recurrences, none died of recurrent disease, 4 were re-operated and are still on follow up. Among these five patients, 3 had N2 lymph node involvement on histopathology, which was not dissected at the time of D1 surgery. Rest 17 D1 patients are following us and are doing well. In modified D2 patients no patient developed recurrence and all 26 patients are surviving.

\section{Conclusions}

After comparing the two types of lymph node dissection procedures, the following conclusions were drawn from the study:

1) Modified $D 2$ gastrectomy took on an average 2 hours longer than $D 1$ gastrectomy;

2) Intra operative blood loss was 150 - $180 \mathrm{ml}$ more in modified $D 2$ gastrectomy than in D1 gastrectomy;

3) Operative mortality was same in both surgeries. Operative morbidity was seen more in modified D2 gastrectomy than D1 gastrectomy but was statistically insignificant;

4) Blood transfusion was more frequently and significantly needed in modified D2 gastrectomy patients than in D1 patients;

5) Hospital stay was marginally longer in modified D2 patients than in D1 patients;

6) Number of dissected lymph node was almost triple in modified D2 patients than in D1 patients;

7) Number of recurrence was quite significant in D1 gastrectomy patients but was not seen in modified D2 patients;

8) Keeping in view the lesser number of recurrences in D2 patients, the longer operative time, blood loss during surgery and increased hospital stay may be considered acceptable.

On the basis of this study, we recommend that modified D2 gastrectomy is a better procedure than D1 gastrectomy. Survival results could not be seen because follow-up period was small, even though the recurrence as well as in-hospital mortality in modified D2 lymphadenectomy group was significantly less than that of D1 or conventional D2 lymphadenectomies. The study will continue in future at least for three more years to formulate survival results. 


\section{References}

[1] Jemal, A., Siegel, R., Ward, E., et al. (2008) Cancer Statistics, 2008. CA: A Cancer Journal for Clinicians, 58, 71-96. http://dx.doi.org/10.3322/CA.2007.0010

[2] Kajitani, T. (1981) The General Rules for the Gastric Cancer Study in Surgery and pathology. Part I. Clinical Classification. Japanese Journal of Surgery, 11, 127-139. http://dx.doi.org/10.1007/BF02468883

[3] Bonenkamp, J.J., Songun, I., Hermans, J., et al. (1995) Randomized Comparison of Morbidity after D1 and Modified D2 Dissection for Gastric Cancer in 996 Patients. The Lancet, 345, 745-748. http://dx.doi.org/10.1016/S0140-6736(95)90637-1

[4] Cuschieri, A., Fayers, P., Fielding, J., et al. (1996) Postoperative Morbidity and Mortality after D1 Modified D2 Resections for Gastric Cancer: Preliminary Results of the MRC Randomized Controlled Surgical Trial. The Lancet, 347, 995-999. http://dx.doi.org/10.1016/S0140-6736(96)90144-0

[5] Soga, J., Kobayahsi, K., Saito, J., Fukimaki, M. and Muto, T. (1979) The Role of Lymphadenectomy in Curative Surgery for Gastric Cancer. World Journal of Surgery, 3, 701-708. http://dx.doi.org/10.1007/BF01654793

[6] Maruyama, K., Okabayashi, K. and Kinoshita, T. (1987) Progress in Gastric Cancer Surgery in Japan and Its Limits of Radicality. World Journal of Surgery, 11, 418-425. http://dx.doi.org/10.1007/BF01655804

[7] Bonenkamp, J.J., Hermans, J., Sasasko, M., et al. (1993) Extended Lymph Node Dissection for Gastric Cancer. The New England Journal of Medicine, 340, 908-14. http://dx.doi.org/10.1056/NEJM199903253401202

[8] Cushieri, A., Weeden, S., Fielding, J., et al. (1999) Patient Survival after D1 and Modified D2 Resections for Gastric cancer: Long Term Results of the MRC Randomized Surgical Trial. BJC, 79, 1522-1530. http://dx.doi.org/10.1038/sj.bjc.6690243

[9] Sue-Ling, H.M., Johnston, D., Martin, I.G., Dixon, M.F., Lansdown, M.R., McMahon, M.J. and Axon, A.T. (1993) Gastric Cancer: A Curable Disease in Britain. BMJ, 307, 591-596. http://dx.doi.org/10.1136/bmj.307.6904.591

[10] Griffith, J.P., Sue-Ling, H.M., Martin, I.G., Dixon, M.F., McMahon, M.J., Axon, A.T. and Johnston, D. (1995) Preservation of the Spleen Improves Survival after Radical Surgery for Gastric Cancer. Journal, 36, 684-690.

[11] Songun, I., Putter, H., Kranenbarg, E.M.K., Sasako, M. and van de Velde, C.J.H. (2010) Surgical Treatment of Gastric Cancer: 15-Year Follow-Up Results of the Randomized Nationwide Dutch D1D2 Trial. The Lancet Oncology, 11, 439-449. http://dx.doi.org/10.1016/S1470-2045(10)70070-X

[12] Degiuli, M., Sasako, M., Ponti, A., Soldati, T., Danese, F. and Calvo, F. (1998) Morbidity and Mortality after Modified D2 Gastrectomy for Gastric Cancer: Results of the Italian Gastric Cancer Study Group Prospective Multicenter Surgical Study. Journal of Clinical Oncology, 16, 1490-1493.

[13] Wu, C.W., Hsiung, C.A., Lo, S.S., et al. (2006) Nodal Dissection for Patients with Gastric Cancer: A Randomized Controlled Trial. The Lancet Oncology, 7, 309-315. http://dx.doi.org/10.1016/S1470-2045(06)70623-4

[14] Wu, C.W., Hsiung, C.A., Lo, S.S., Hsieh, M.C., Shia, L.T. and Whang-Peng, J. (2004) Randomized Clinical Trial of Morbidity after D1 and D3 Surgery for Gastric Cancer. British Journal of Surgery, 91, 283-287. http://dx.doi.org/10.1002/bjs.4433

[15] Degiuli, M., Sasasko, M., Ponti, A., et al. (2014) Morbidity and Mortality in Italian Gastric Cancer Study Group Randomized Clinical Trial of D1 versus Modified D2 Resection for Gastric Cancer. British Journal of Surgery, 101, 23-31. http://dx.doi.org/10.1002/bjs.9345

[16] Danielson, H., Kokkola, A., Kiviluoto, T., Siren, J., et al. (2007) Clinical Outcome after D1 versus D2-3 Gastrectomy for Treatment of Gastric Cancer. Scandinavian Journal of Surgery, 96, 35-40.

[17] Lewis, W.G., Edwards, P., et al. (2002) D2 or Not D2? The Gastrectomy Question. Gastric Cancer, 5, $29-34$. http://dx.doi.org/10.1007/s101200200004

[18] Edwards, P., Blackshaw, G.R.J.C., Lewis, W.G., Barry, J.D., Allison, M.C. and Jones, D.R.B. (2004) Prospective Comparison of D1 vs. Modified D2 Gastrectomy for Carcinoma. British Journal of Cancer, 90, 1888-1892. http://dx.doi.org/10.1038/sj.bjc.6601790

[19] Strong, J.P., Baldizón, C., Salas, J., McMahan, C.A. and Mekbel, S. (1967) Mortality from Cancer Stomach in Costa Rica. Cancer, 20, 1173-1180. http://dx.doi.org/10.1002/1097-0142(196707)20:7<1173::AID-CNCR2820200721>3.0.CO;2-C

[20] Wanebo, H.J., Kennedy, B.J., Chmiel, J., Steele, G., Winchester, D. and Osteen, R. (1993) Cancer of Stomach. A Patient Care Study by American College of Surgeons. Annals of Surgery, 218, 583-592. http://dx.doi.org/10.1097/00000658-199321850-00002

[21] Huang, C.-M., Lin, J.-X., Zheng, C.-H., Li, P., Xie, J.-W. and Wang, J.-B. (2011) Impact of the Number of Dissected 
Lymph Nodes on Survival for Gastric Cancer after Distal Subtotal Gastrectomy. Gastroenterology Research and Practice, 2011, Article ID: 476014.

[22] Methasate, A., Trakarnsanga, A., Akaraviputh, T., Chinsawangwathanakol, V. and Lohsiriwat, D. (2010) Lymph Node Metastasis in Gastric Cancer: Result of Modified D2 Dissection. Journal of the Medical Association of Thailand, 93, 310-317.

[23] Sano, T., Sasako, M., Yamamoto, S., Nashimoto, A., Kurita, A., Hiratsuka, M., et al. (2004) Gastric Cancer Surgery: Morbidity and Mortality Results from a Prospective Randomized Controlled Trial Comparing Modified D2 and Extended Para-Aortic Lymphadenectomy_-Japan Clinical Oncology Group Study 9501. Journal of Clinical Oncology, 22, 2767-2773. http://dx.doi.org/10.1200/JCO.2004.10.184

[24] Kinoshita, T., Maruyama, K., Sasako, M. and Okajima, K. (1993) Treatment Results of Gastric Cancer Patients: Japanese Experience. In: Nishi, M., Ichikawa, H., Nakajima, T., Maruyama, K. and Tahara, E., Eds., Gastric Cancer, Springer, Tokyo, 319-330. http://dx.doi.org/10.1007/978-4-431-68328-5_23

[25] Cushieri, A., Fayers, P., Fielding, J., et al. (1996) Prospective Morbidity and Mortality after D1 and modified D2 Resections for Gastric Cancer: Preliminary Results of the MRC Randomized Controlled Surgical Trial. The Lancet, 347, 995-999. http://dx.doi.org/10.1016/S0140-6736(96)90144-0 